\title{
ERRATA
}

\section{Erratum: Anomalous light absorption in molecular crystals [JETP 85, 554-564 (September 1997)]}

V. I. Tovstenko

Institute of Physics, Ukrainian National Academy of Sciences, 25260 Kiev, Ukraine

Zh. Éksp. Teor. Fiz. 113, 1915 (May 1998)

[S1063-7761(98)02505-0]

On page 555 the last term in Eq. (1) should be: $\sum_{\mathbf{n m}}{ }^{\prime} M_{\mathbf{n m}}^{0} V_{\mathbf{m}}^{+} V_{\mathbf{n}} B_{\mathbf{m}}^{+} B_{\mathbf{n}}$.

\section{Erratum: On the nature of turbulence [JETP 86, 107-114 (January 1998)]}

L. N. Pyatnitskiı̆

Institute of High Temperatures, Russian Academy of Sciences, 127412 Moscow, Russia

Zh. Éksp. Teor. Fiz. 113, 1916 (May 1998)

[S1063-7761(98)02605-5]

On page 111, the figure should have a caption reading: FIG. 2. Structure of the flow in front of the flame. 